\title{
Sustainable metal management exemplified by copper in the USA
}

\author{
C. Zeltner - H.-P. Bader - R. Scheidegger - P. Baccini
}

\begin{abstract}
A sustainable management of nonrenewable metals calls for scientific-ecological understanding of the regional material household. The copper household in the USA between 1900 and 2100 was chosen to illustrate mathematical modelling of such systems. Relatively limited and inaccurate sets of data already allow a first approximation of the metal management system. The copper fluxes of the 20th century have contributed to the formation of two new ore deposits of the same order of magnitude as the currently still available reservoir (90 million tons), i.e. copper stock in consumption products (approx. 70 million tons) and in landfills (approx. 40 million tons). The "landfill", therefore, contains copper whose potential use is lost due to dilution. The long-term copper consumption stock is greater than the shortterm stock. Scenarios show that the current economically mineable $\mathrm{Cu}$-stocks will be exhausted in 30 to 50 years if a change in the existing management system does not occur. In case of a reorientation, the use of copper as a "new resource" in the consumption stocks appears to be the most promising strategy. The future waste management processes will have to increase their copper recycling rates.
\end{abstract}

\section{Introduction}

Copper was probably the first metal employed by man. It has been processed since the 5th millennium B.c., both in its pure form and also in alloys such as bronze or brass. The global, potentially mineable copper resources are

Received: 24 February 1999 - Accepted: 8 June 1999

C. Zeltner · P. Baccini

Chair of Resource and Waste Management, Swiss Federal Institute of Technology, Zurich, Switzerland

H.-P. Bader · R. Scheidegger ( $\varangle)$

S+E Department, EAWAG, CH-8600 Duebendorf, Switzerland e-mail: ruth.scheidegger@eawag.ch; Fax: +41-1-8235028 estimated at 2.3 billion tons, of which 0.5 billion tons are currently considered as economically mineable (Black and Lyman 1990). In addition, it was estimated that by the end of the 1980s, 320 million tons of copper had already been mined, of which three quarters since 1945 . More than $90 \%$ of the copper is used as copper metal $\left(\mathrm{Cu}^{0}\right)$, namely as pure copper, brass and bronze. Till the beginning of modern times, copper was primarily used for its mechanical and aesthetic properties. Since the end of the 19th century, it has been mainly used as an electric conductor to transfer both energy and information. Furthermore, metallic $\mathrm{Cu}$ is used in the building industry for its resistance to corrosion, and in air-conditioning technology for its good heat conductivity. Figure 1 depicts a classification according to business sectors and primarily used properties according to the $1989 \mathrm{Cu}$ consumption in the USA. Copper is produced through smelting of ores in combination with qualitatively low-grade copper scrap. A large amount of high-grade copper scrap and pure alloy scrap is directly melted in tube mills.

Scrap is classified into two general categories called old scrap and new scrap, depending on its origin. Old scrap is generated from worn-out, discarded, or obsolete copper products. New scrap, or manufacturing scrap, is generated during the fabrication of copper products. It is called "run-a-round" or home scrap when it is generated internally at the plant consuming it. Thus the quality of the scrap is more important than its origin. The Institute of Scrap Recycling Industries Inc. (ISRI) recognizes more than 50 classes (qualities) of copper and copper alloy scrap (Jolly and Edelstein 1989). Examination of the metal statistics reveals that in the listed countries, aside from the USA, the scrap is not generally classified into new and old scrap (a selection is illustrated in Table 1). It can be postulated generally that these data are not identical to the copper consumption in the relevant countries. The reasons are the following: (1) USA, Japan, Germany, and Chile are copper-producing and -exporting countries. (2) All countries are copper-importing countries, mainly through copper-containing consumer goods.

The per capita production of refined copper is the same for the USA, Japan and Germany (approx. 6-9 kg per capita per year). The specific production of goods in these three countries is roughly twice as high (about $12-18 \mathrm{~kg}$ per capita per year). Chile, for example, is a country that mainly exports its refined copper, but manufactures comparatively little. Germany uses the highest amount of scrap for its production of refined copper (61\%). 


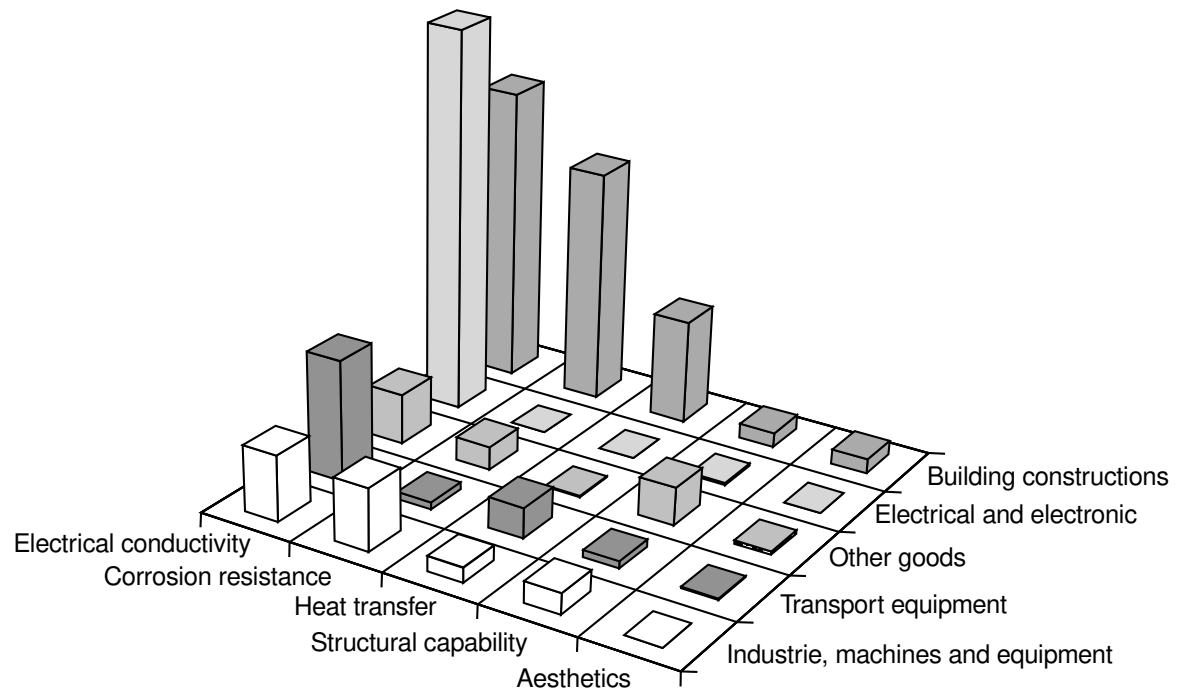

Fig. 1

$\mathrm{Cu}$ consumption of the manufacturing industries in the USA (1989) classified according to business sectors and primarily used characteristics (Black and Lyman 1990)

Table 1

Data on copper industries in various countries and worldwide (Metallgesellschaft AG 1992). For the production of refined copper, the $\mathrm{Cu}$ metal is obtained from ores and from qualitatively

low-grade scrap (mainly old scrap). The $\mathrm{Cu}$ flux in the manufacturing industries is made up of refined copper and directly melted down to $\mathrm{Cu}$ scrap (mainly new scrap). ? No data available

\begin{tabular}{|c|c|c|c|c|c|c|c|c|}
\hline \multirow[t]{2}{*}{ Country } & \multirow{2}{*}{$\begin{array}{l}\text { Population } \\
\text { (millions) }\end{array}$} & \multicolumn{3}{|c|}{$\mathrm{Cu}$ flux from production of refined copper } & \multicolumn{4}{|c|}{$\mathrm{Cu}$ flux into the manufacturing industries } \\
\hline & & $(1000 \mathrm{t} /$ year $)$ & $\begin{array}{l}\text { (kg per capita } \\
\text { per year) }\end{array}$ & $\begin{array}{l}\text { Scrap } \\
\text { fraction }\end{array}$ & $\begin{array}{l}(1000 \mathrm{t} / \\
\text { year })\end{array}$ & $\begin{array}{l}\text { (kg per } \\
\text { capita } \\
\text { per year) }\end{array}$ & $\begin{array}{l}\text { Directly } \\
\text { melted } \\
\text { down scrap } \\
\text { fraction }\end{array}$ & $\begin{array}{l}\text { Total scrap } \\
\text { fraction } \\
\text { (new+old) }\end{array}$ \\
\hline USA & 250 & 2000 & 8.0 & $21 \%$ & 2900 & 11.6 & $29 \%$ & $44 \%$ \\
\hline Japan & 124 & 1080 & 8.7 & $10 \%$ & 2280 & 18.4 & $29 \%$ & $34 \%$ \\
\hline Germany & 80 & 520 & 6.5 & $61 \%$ & 1240 & 15.5 & $19 \%$ & $45 \%$ \\
\hline Chile & 13 & 1200 & 92 & ? & 47 & 3.6 & $?$ & ? \\
\hline Switzerland & 7 & - & - & - & 32 & 4.5 & $86 \%$ & $86 \%$ \\
\hline World & 5300 & 10,600 & 2.0 & $?$ & 15,200 & 2.9 & $30 \%$ & $?$ \\
\hline
\end{tabular}

Switzerland, in turn, has no copper-refining industry. Its manufacturing industry is characterized by its high fraction of new scrap (86\%).

At the beginning of the 1990s, the global per capita production of goods amounted to about $3 \mathrm{~kg} /$ year, using 30\% recycled copper (scrap). In industrialized countries the production of goods is several times higher.

The average copper price between 1979-1988 was about $\$ 2 / \mathrm{kg}$ (based on this price, the copper needed in the USmanufacturing industries has a value of $\$ 23$ per capita). Price fluctuations of $10 \%$ from month to month occur quite often (Metallgesellschaft 1992). Throughout this century up to 1990, the mean copper prices over a decade varied between a low of $\$ 1.9(1930-1939)$ to a high of $\$ 4.8 /$ kg (1910-1919; Jolly and Edelstein 1989). Prices depend strongly on supply and demand and therefore also on the world economy. Also, different governmental monetary, trade and other policies have and have had a significant impact on the supply and demand of copper. Actual prices are very low (1998, $\$ 1.7 / \mathrm{kg})$.

Data on $\mathrm{Cu}$ consumption in the various countries are practically non-existent. To assess the properties of regional copper management, it is necessary to view production, processing, consumption, and waste treatment as a whole. Examination of the statistical data reveals that larger countries with their own copper industry are best suited for this purpose. The USA certainly possesses the world's largest compilation of statistical data on the management of $\mathrm{Cu}$ metal. $\mathrm{Cu}$ consumption is classified according to business sectors (Metallgesellschaft 1992). The generated scrap is classified into new scrap (scrap from production) and old scrap (scrap from waste treatment of $\mathrm{Cu}$-containing products). Due to the particularly important home market, it is also possible to gain insight into the consumption of $\mathrm{Cu}$-containing products.

To describe the regional material management, it is important to distinguish between two levels, namely the socio-economic and the ecological level. The present report, which focuses only on the second level, deals with the following questions:

1. Where and how large are the geogenic and anthropogenic $\mathrm{Cu}$ stocks?

2. How do the stocks evolve in time? 
3. What are the conclusions for a sustainable metal management?

\section{Method}

\section{System analysis}

Material flux analysis is used to determine and mathematically describe regional copper management (Baccini and Bader 1996). First, relevant processes and products are selected which represent the copper management system of the USA within the chosen boundaries (Fig. 2).

The ten processes of the system are divided into three groups:

\section{Supply processes}

1. Mining

2. Crushing and flotation

3. Smelting and refining

4. Production of semi-manufactured products

5. Production of goods

\section{Consumption processes}

1. Consumption of long-term products

2. Consumption of short-term products

Waste management processes

1. Dismantling and demolition

2. Separate collection

3. Landfilling

The following assumptions and simplifications were made for the individual parts of the system:

- The copper fluxes to the environmental compartments (soil, water, air) are not taken into consideration in this analysis due to their minor importance in the total turnover. Switzerland's environmental compartment fluxes are estimated at $0.1 \mathrm{~kg}$ per capita per year (Von Arx 1996). This corresponds only to a small percentage of the total turnover and also lies within the error margin of such investigations. Copper emissions are generated mainly through dust emissions in thermal processes and corrosion of used products. Although the resulting immissions can be of ecotoxicological relevance, they are not assessed in this study.

- Since copper imports and exports are assumed to be of the same order of magnitude in the USA, these fluxes are not taken into account. This is true for copper-rich, long-term product groups, such as electronic equipment of power and air-conditioning units (Department of Economic and Social Development Statistical Office 1992). For short term products, such as vehicles and computers, import is higher than export. Import of vehicles (including buses and trucks), for example, is three times higher (Verband der Automobilindustrie 1997) and amounts to about $30 \%$ of the total consumption. Moreover, because an unknown quantity of used vehicles is exported from the USA, it is appropriate to assume an approximatively even import-export balance also in regard to $\mathrm{Cu}$-containing, shortterm products.

- The flux new scrap (production waste) in Fig. 2 summarizes fluxes reported in the supply statistics. To visualize this flux of goods, all new scrap is assumed to be generated during the manufacturing process of goods and melted down for the production of semi-manufactured products. The consumption and waste management processes are simplified even further. The thousand different $\mathrm{Cu}$-containing products are classi-

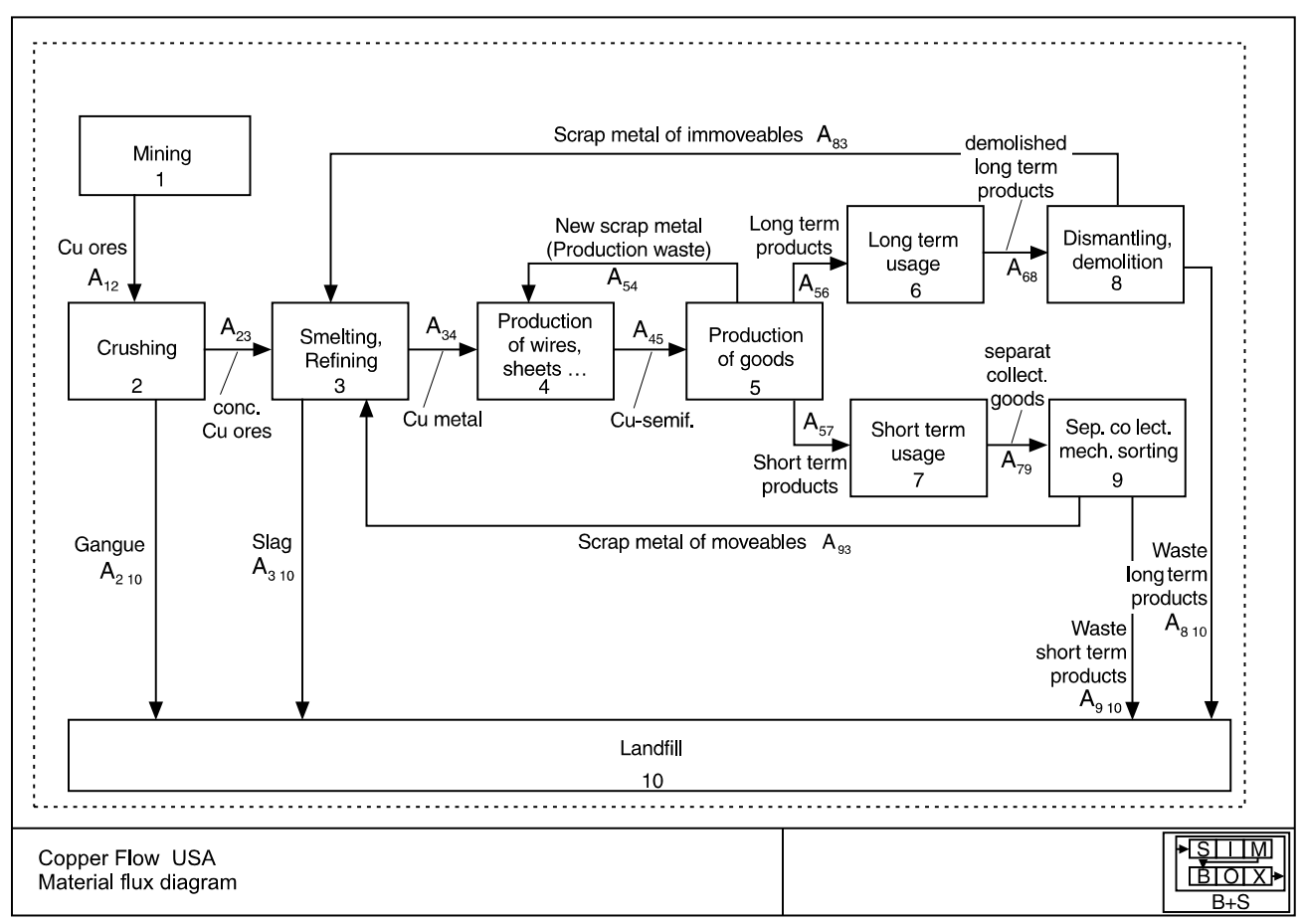

Fig. 2

System description of the copper household in the USA 
fied into two product groups, i.e. short-term and longterm products. Both groups differ primarily with regard to lifetime and applied technology in waste treatment.

- The geographic boundaries of the USA are used as system boundaries only for the consumption and waste management processes. The supply processes also comprise the fluxes of copper generated by USA consumption outside its nationale boundaries, e.g. mining.

\section{Data sources for the estimation of copper fluxes and stocks}

A detailed description of the ten processes chosen, their fluxes and stocks (see Fig. 2) is given in the following:

1. Mining: The mines contain the available ore deposits of the USA and the ore required for US consumption. Roughly $95 \%$ of the currently mined copper occurs as sulfide ores. The average copper concentration of the mined ores dropped from $>2 \%$ at the beginning of this century to presently about $0.5 \%$. The USA can currently meet over $80 \%$ of its own copper demand. The present mineable copper ores in the USA are estimated at 90 million tons (Black and Lyman 1990).

2. Crushing, flotation: The ores are first crushed in jaw and roll crushers and subsequently finely ground in ball mills. The powders are then separated according to density and wetting behaviour in multi-stage flotation plants. The resulting ore concentrate contains $20-30 \%$ copper and gangue (country rock) of $0.05 \%$ average copper concentration (Biswas and Davenport 1994).

3. Smelting, refining: Various process combinations are used to smelt the sulfide ores. The ores are first subjected to a drying or roasting process before undergoing several metallurgical smelting processes (shaft or reverberatory furnace, converter and fire refining). The copper-rich slag of the converter and refining process is returned to the shaft/reverberatory furnace. The produced copper residues from smelting are only contained in the slag of the shaft or reverberatory furnace. In the reverberatory furnace process of Noranda Mines Ltd., for example, the 90 tons of copper daily generate 1000 tons of slag with a copper concentration of $0.3 \%$ (Biswas and Davenport 1994). The last refining step comprises a wet-chemical process in which copper anodes are electrolytically converted into pure copper cathodes (refined copper). No major losses of copper occur during this process. Old scrap (in long-term and short-term products) is produced by two waste management processes (dismantling/demolition and waste treatment). Old scrap differs greatly in quality, i.e. its copper content varies between 20 and $99 \%$. It is used most commonly in the smelting processes (low copper contents) or in one of the various refining processes (high copper contents). The fraction of copper lost per ton of refined copper for old scrap is approximately the same as that from the smelting and refining processes of the copper ore concentrates (Bruch et al. 1996).
4. Production of semi-manufactured products: Copper is processed into semi-manufactured products (wires, pipes, sheet metals, castings). Most of the copper used is pure copper. About one third of the copper is melted down into alloys (brass, bronze) in foundries, rolling and wire mills. A small part of the copper is processed by powder metallurgy. Apart from refined copper, new scrap is also remelted.

5. Manufacturing industries: The copper-containing, semi-manufactured products are integrated into shortterm and long-term products. New scrap is the by-product of the manufacturing industries.

6. Consumption of long-term products.

7. Short-term products: The two processes include storing and use of copper-containing products. Their outputs are the used products in the waste management processes (dismantling/demolition and waste disposal), hereafter referred to as old long-term and old short-term products.

8. Waste disposal: Disposal of old short-term products takes place as separately collected products or as solid municipal waste. The copper contained in municipal waste reaches landfills either through direct landfilling or through thermal treatment in grate furnaces. Separation efficiency of the sorting process for separately collected products also depends on the way copper is embedded in the products (copper is present, e.g. in cables, windings or electronic components). There are also different size-reduction techniques (manual disassembly, different shredding methods) and separation techniques (manual and magnetic separation, flotation and air separation). As a result of the ever-increasing quantities of electronic scrap, a great variety of innovative sorting technologies are being developed whose separation efficiencies and quantitative importance are still unknown. For the management system it is crucial to know how much old scrap from short term products is being recycled (recycling efficiency). Studies on the balance of the whole waste management system have not been made.

9. Demolition, dismantling: Copper recycling from old long-term products should be more efficient than from short-term products. It is assumed that copper is easy to recover from big plants and networks (electrical conductors). In buildings this appears to be more difficult. Data from copper recycling from buildings are practically unavailable.

10. Landfilling: This process is the sink for all copper whose potential use as metal is lost. This comprises the landfilled $\mathrm{Cu}$-containing residues from the copper industry, i.e. gangue and slag, as well as the residues from demolition and waste treatment. $\mathrm{Cu}$-containing residues are also used partly as building material (e.g. lump slag as a gravel substitute). An important sink for copper are the ferrous products. A great deal of copper remains in the iron scrap fraction during separation for recycling. Thus, the copper is incorporated in the recycled steel. Copper cannot be separated metallurgically by iron smelting. 
Copper consumption of the manufacturing industries in the USA is statistically reported according to product groups (Black and Lyman 1990). Table 2 lists these product groups which are classified in the system (Fig. 2) as long-term and short-term products. The changes in copper consumption from 1989 are also compared with the 1975 consumption (index 100) for each product group.

Long-term products

Limited information is available on the lifetime of copper contained in long-term products. As described in Baccini and Brunner (1991), the average lifetime of buildings in the 20th century is estimated at 70 years and that of installations at 30 years. The average lifetime of copper in long-term products is assumed to vary between 30 and 70 years. The following additional information is provided for the individual product groups:

- Building wiring: Copper cables are used for the distribution of electric current in buildings, in new installations and also for new wiring (as replacement or auxiliary) of existing buildings. Although the construction rate of new buildings has remained approximately constant from 1975 to 1989 , the consumption of copper has doubled over this period.

- Plumbing and heating: Copper is used in water pipes, especially in hot water and pressure pipes. Plastic pipes have appeared as a competitive product on the market. An increasing number of such installations per house has also been observed.

- Telecommunications: Here, copper is mainly found in the telephone system which is rapidly expanding and becoming multi-functional. Since 1980, copper has increasingly been replaced by glass fibre cables (first in

\section{Table 2}

Copper consumption of the manufacturing industries in the USA for the different product groups in 1989 and changes in consumption in relation to 1975, classified according to long-term and short-term usage. (Black and Lyman 1990) ? No data available

\begin{tabular}{|c|c|c|}
\hline Product groups & $\begin{array}{l}\text { Cu consumption } \\
1989 \text { (million } \\
\text { kg/year) }\end{array}$ & $\begin{array}{l}\text { Relative change } \\
\text { in consumption } \\
(1975 \text { index } \\
100)\end{array}$ \\
\hline Long-term products & 2020 & \\
\hline Building wiring & 540 & 200 \\
\hline Plumbing and heating & 450 & 120 \\
\hline Telecommunications & 250 & 70 \\
\hline Electric power utilities & 240 & 110 \\
\hline $\begin{array}{l}\text { Air-conditioning and } \\
\text { refrigeration }\end{array}$ & 220 & 150 \\
\hline In-plant equipment & 220 & 90 \\
\hline $\begin{array}{l}\text { Industrial valves and } \\
\text { fittings }\end{array}$ & 100 & 160 \\
\hline Short-term products & 460 & \\
\hline $\begin{array}{l}\text { Automotive electrical } \\
\text { and non-electrical }\end{array}$ & 310 & 110 \\
\hline Business electronics & 150 & 280 \\
\hline Other products & 630 & $?$ \\
\hline
\end{tabular}

the lines between the telephone exchanges, but currently also in the fine distribution).

- Electric power utilities: Copper cables are used in the generation, transformation and distribution systems of electricity (80\% of the copper is used in distribution).

- Air-conditioning and refrigeration: Copper is primarily used in these installations due to its good heat conductivity.

- In-plant equipment: In this product group, copper is mainly used in windings of large engines.

- Industrial valves and fittings: Fittings are mainly made of brass.

Short-term products

The lifetime of short-term products amounts to approximately 10 years according to Baccini et al. (1993). In the following is some information concerning the individual product groups:

- Automotive electrical and non-electrical: Copper is used in the electrics of vehicles (including busses and trucks) due to its electrical conductivity, in the windings of the ever-increasing number of small engines and in cable looms of power distribution systems. Copper is also found in the cooling systems of non-electrical products. Since 1980, however, cooling systems have increasingly been replaced by aluminium.

- Business electronics: Business electronics comprises computers, peripherals, copying equipment, etc. The significant increase in copper consumption in this field can be attributed to the growth of the computer industry.

Other products

Roughly $20 \%$ of the annual copper consumption is not covered by the nine selected product groups.

\section{Mathematical description}

The mathematical description of the presented copper household system described in Fig. 2 is based on the procedure of Baccini and Bader (1996).

Set of variables

The first step is to define a set of variables for a complete description of the system.

Twenty five variables describe the system in Fig. 2, namely:

$$
\begin{array}{r}
M^{(1)}(t), \ldots, M^{(10)}(t): \text { amount of material } \\
\text { of the ten processes }
\end{array}
$$

$$
A_{12}(t), A_{23}, \ldots, A_{810}(t): 15 \text { fluxes }
$$

$M^{(i)}(t)$ expresses the stock in the process $i$ or, physically, the amount of material in the balance volume $V_{i} \cdot A_{r s}(t)$ denote the material fluxes between the individual processes. 


\section{Available data}

A complete description of the copper household requires the knowledge of the 25 variables at time $t$ - in this case for the year 1990. In the best case, measurements with confidence intervals (and if possible correlations) for all these variables over different time periods are available. A statistical analysis (least square fit) would then lead to the best estimates for the copper household at time $t$. In practice, however, such time series are not or only partly available. Reliable data possibly exist on copper fluxes in relation to the copper supply: copper in ore, copper in ore concentrate, copper in gangue, refined copper, copper fluxes in slag, copper in semi-manufactured products, copper in new scrap, copper in the entire old scrap, copper consumption for products.

However, the available data on the consumption processes (stock and changes in stock) and on the waste management processes (copper in old long-term and old shortterm products, as well as in the residues) are insufficient. The limited data can also be attributed to the very complex determination of $\mathrm{Cu}$ contents in products and residues. More recently, tedious analyses of manually collected municipal solid waste bottom ashes (Zeltner 1998; Frey and Hugentobler 1996) showed $\mathrm{Cu}$ contents of $8 \mathrm{~g} / \mathrm{kg}$. These values are two to four times higher than the values obtained from older analyses, where the metal fraction was not or only insufficiently taken into consideration.

Prior to filling the identified data gaps with further series of measurements, which could be a very complex and time-consuming task, a few experimental data and estimated values of the copper household system in Fig. 2 could serve as a first approximation. Here, sensitivity analyses and error propagation can be used to discuss the most realistic range for all the fluxes and stocks of the copper household system.

\section{Model specification}

The stock has been built up by accumulating copper over the years from the beginning of ore mining. Therefore, the system is time-dependent, which means that a dynamic model should be used. The system equations, mathematically linking and describing the data and assumptions used, are the core of the model specification. Thus a distinction is made between the general and system-specific equations.

General equations: The physical mass conservation reveals for each individual balance volume (each process) a balance equation.

$$
\begin{aligned}
& F_{1}=\dot{M}^{(1)}(t)+A_{12}(t)=0 \\
& F_{2}=\dot{M}^{(2)}(t)-A_{12}(t)+A_{23}(t)+A_{210}(t)=0 \\
& \vdots \\
& F_{10}=\dot{M}^{(10)}(t)-A_{210}(t)-A_{310}(t)-A_{810}(t)-A_{910}(t)=0
\end{aligned}
$$

whereby $\dot{M}^{(i)}(t)$ is the derivative of $M^{(i)}(t)$ with respect to time.
System-specific equations: These equations mathematically express the assumptions concerning the system. These assumptions can be divided into two groups: (1) assumptions on production and consumption of goods, (2) assumptions related to copper supply and disposal.

Production and consumption of goods The assumptions are based on a dynamic input-output model:

$$
\begin{gathered}
F_{11}=A_{45}(t)-P_{1}(t)=0 \\
F_{12}=\frac{A_{54}(t)}{A_{45}(t)}-P_{2}(t)=0 \\
F_{13}=\frac{A_{57}(t)}{A_{56}(t)}-P_{3}(t)=0 \\
F_{14}=A_{68}(t)-\int_{0}^{t} k_{\text {longterm }}\left(t, t^{\prime}\right) A_{56}\left(t^{\prime}\right)\left(d t^{\prime}\right)=0 \\
F_{15}=A_{79}(t)-\int_{0}^{t} k_{\text {shortterm }}\left(t, t^{\prime}\right) A_{57}\left(t^{\prime}\right)\left(d t^{\prime}\right)=0
\end{gathered}
$$

The equations, thus, express the following:

Equation (3a): Given total copper consumption in shortand long-term products. The parameter function $P_{1}(t)$ is, therefore, the assumed development of copper consumption as a function of time.

Equation (3b): New scrap copper is proportional to the copper found in semi-manufactured products. The proportional factor $P_{2}(t)$ can be time-dependent.

Equation (3c): The parameter function $P_{3}(t)$ corresponds to the ratio of copper consumption in short-term to long-term products.

Equation (3d), (3e): Dynamic input-output relations between copper consumption (input) and copper disposal (output) for long-term and short-term products. $k_{\text {longterm }}\left(t, t^{\prime}\right)$ and $k_{\text {shortterm }}\left(t, t^{\prime}\right)$ are, consequently, the transfer functions (parameter functions $P_{4}$ and $P_{5}$ ) for the long-term and short-term products, respectively. They express the amount of input at time $t^{\prime}$, leaving the consumption processes as output at time $t$.

Equations (3d) and (3e) are, in principle, a mathematical description of the fact that products in the long-term and short-term consumption processes have a statistically defined residence time.

The parameter functions are defined and adapted during calibration of the model (see "Calibration of the model").

Copper supply and disposal In the processes 2-5 and 8-9 (see "Data sources for estimation of copper fluxes and stocks"), the change in stock can be neglected, i.e.: 


$$
\begin{aligned}
& F_{16}=\dot{M}^{(2)}(t)=0 \\
& F_{17}=\dot{M}^{(3)}(t)=0 \\
& F_{18}=\dot{M}^{(4)}(t)=0 \\
& F_{19}=\dot{M}^{(5)}(t)=0 \\
& F_{20}=\dot{M}^{(8)}(t)=0 \\
& F_{21}=\dot{M}^{(9)}(t)=0
\end{aligned}
$$

This assumption is reasonable for the examined balance period of 1 year, as important stock accumulations are undesirable owing to economic considerations.

Further assumptions regarding the copper supply are:

$$
\begin{gathered}
F_{22}=\frac{A_{210}(t)}{A_{12}(t)}-P_{6}(t)=0 \\
F_{23}=\frac{A_{310}(t)}{A_{23}(t)+A_{83}(t)+A_{93}(t)}-P_{7}(t)=0
\end{gathered}
$$

Similarly as above, Eqs. (5a) and (5b) express:

Equation (5a): Copper in the gangue material is proportional to the copper in the mined ore reservoir. The proportional factor $P_{6}(t)$ can be time-dependent.

Equation (5b): The copper losses through the slag in the smelting and refining process are proportional to the total input into this process. The proportional factor $P_{7}(t)$ can again be time-dependent.

The following are assumptions for the waste management of copper-containing products:

$$
\begin{aligned}
& F_{24}=\frac{A_{83}(t)}{A_{810}(t)}-P_{8}(t)=0 \\
& F_{25}=\frac{A_{93}(t)}{A_{910}(t)}-P_{9}(t)=0
\end{aligned}
$$

These two equations mean that the ratio recycling/landfilling is given for long-term and short-term products (parameter functions).

In summary, a total of 25 system equations are given for the 25 system variables. The system variables can thus be calculated if their initial values are known.

Initial values

The initial condition is characterized by the fact that all the fluxes and stocks, except for $M^{1}(0)$ (mining process), are assumed to be zero. $M^{1}(0)$ expresses the estimated copper ore deposit before mining began.

\section{Calibration of the model}

The chosen unit of the fluxes is million tons per year. Note that demographic development is included in these fluxes. The per capita values (kg per capita per year, e.g. 1990) can be easily obtained by dividing through the number of inhabitants.

The nine parameter functions in the system Eqs. (2), (3), (4), (5), and (6) are the quantities determining the development of the system. In particular, each set of parameter functions induces a corresponding development of the system as a function of time. Changes in the parameter functions, therefore, allow specific modifications of the system. This leads to an understanding of the system, which is of particular importance when planning and implementing improvements of the system in the sense of a more sustainable management.

However, prior to discussing system modifications, the set of parameter functions best describing the past should be determined. This step involves a calibration of the model (parameter adjustment) to determine the most adequate parameter functions concerning the available data. This requires a best fit to known time series. The criteria for the choice of the parameter functions are as follows:

1. the parameter functions are as simple as possible 2. the number of parameters is as small as possible Note that these criteria are, in principle, quality criteria for good models.

$P_{1}(t)$ Copper consumption as a function of time Figure 3 illustrates the reports of copper consumption from the literature (Metallgesellschaft 1992) for the manufacturing industries in the USA between 1900 and 1990. It is evident that many parameter functions fit the copper consumption as a function of time in Fig. 3. Therefore two different parameter functions were chosen and fitted. The simplest strategy is linear:

$$
P_{1}(t)=p_{1,1}+p_{1,2} \cdot(t-1900): \text { linear growth }
$$

The somewhat more difficult logistic growth should also be examined to assess future development:

$$
P_{1}(t)=\frac{p_{1,1}}{p_{1,2}+\left(1-p_{1,2}\right) e^{-p_{1,3} \cdot(t-1900)}}: \quad \text { logistic growth }
$$

The quantities $p_{i, j}$, thus, express individual parameters belonging to the $P_{i}(t)$ parameter function.

These parameters are determined in such a way that $P_{1}(t)$ best fits the development of Fig. 3 (linear and non-linear regression, respectively). Both the calibrated parameter values for $P_{1}(t)$ and those for all the other parameter functions are listed in Table 3.

Only the future will reveal the difference between strategies (7a) and (7b): Eq. (7a) expresses continued growth and 
Eq. (7b) pertains to a state of saturation. Equations (7a) and (7b), therefore, correspond to two different future scenarios.

$$
P_{2}(t), P_{3}(t), P_{6}(t), P_{7}(t)
$$

These parameter functions denote time-dependent transfer coefficients for instantaneous input-output processes. For reasons of plausibility and because the relevant database does not allow other alternatives, all these functions are assumed to be constant as a function of time. This simplification is justified for a first approximation, as confirmed, for instance, for $P_{2}$. The ratio

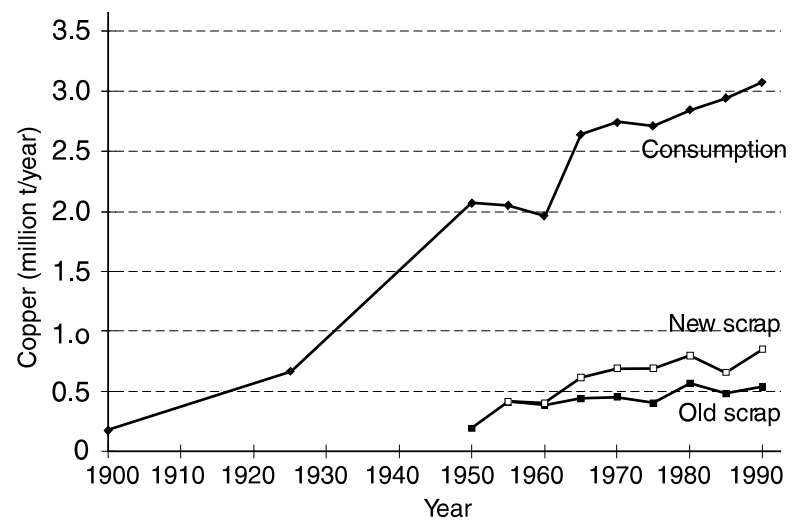

Fig. 3

Development of the $\mathrm{Cu}$ consumption in the manufacturing industries, including appearance of new and old scrap in the USA, compiled from data on metal statistics (Metallgesellschaft AG 1992)

Table 3

Parameters for scenarios 1 to 8 (Sc 1-8) for linear and logistic growth $\left(P_{1}\right.$ to $P_{3}$ and $P_{6}, P_{7}$ calibrated directly from the raw data;

\begin{tabular}{|c|c|c|c|c|c|c|c|c|c|}
\hline \multicolumn{2}{|c|}{ Parameter functions and corresponding parameters } & \multirow{2}{*}{$\frac{\text { Sc } 1}{0.11}$} & \multirow{3}{*}{$\begin{array}{l}\text { Sc } 2 \\
0.11 \\
0.035\end{array}$} & \multirow{3}{*}{$\begin{array}{l}\text { Sc } 3 \\
0.11 \\
0.035\end{array}$} & \multirow{3}{*}{$\begin{array}{l}\text { Sc } 4 \\
0.11 \\
0.035\end{array}$} & \multirow[t]{3}{*}{ Sc 5} & \multirow[t]{3}{*}{ Sc 6} & \multirow[t]{3}{*}{ Sc 7} & \multirow[t]{3}{*}{ Sc 8} \\
\hline$P_{1}^{\mathrm{a}}$ linear & $P_{1,1}($ million $\mathrm{t} /$ year $)$ & & & & & & & & \\
\hline & $P_{1,2}($ million $\mathrm{t} /$ year $)$ & 0.035 & & & & & & & \\
\hline \multirow{3}{*}{$P_{1}^{a}$ logistic } & $P_{1,1}($ million $\mathrm{t} /$ year $)$ & & & & & 0.18 & 0.18 & 0.18 & 0.18 \\
\hline & $P_{1,2}$ & & & & & 0.057 & 0.057 & 0.057 & 0.057 \\
\hline & $P_{1,3}^{1,2}(1 /$ year $)$ & & & & & 0.062 & 0.062 & 0.062 & 0.062 \\
\hline$P_{2}^{\mathrm{b}}$ & $P_{2,1}$ & 0.24 & 0.24 & 0.24 & 0.24 & 0.24 & 0.24 & 0.24 & 0.24 \\
\hline$P_{3}^{\mathrm{c}}$ & $P_{3,1}^{2,1}$ & 0.22 & 0.22 & 0.22 & 0.22 & 0.22 & 0.22 & 0.22 & 0.22 \\
\hline \multirow[t]{2}{*}{$P_{4}^{\mathrm{d}}=k_{\text {longterm products }}$} & $\tau_{I}($ year $)$ & 30 & 50 & 70 & 90 & 30 & 50 & 70 & 90 \\
\hline & $\sigma_{I}$ (year) & 20 & 30 & 40 & 50 & 20 & 30 & 40 & 50 \\
\hline \multirow[t]{2}{*}{$P_{5}^{\mathrm{d}}=k_{\text {shortterm products }}$} & $\tau_{M}$ (year) & 5 & 10 & 15 & 20 & 5 & 10 & 15 & 20 \\
\hline & $\sigma_{M}$ (year) & 3 & 7 & 10 & 15 & 3 & 7 & 10 & 15 \\
\hline$P_{6}^{\mathrm{e}}$ & $P_{6,1}$ & 0.1 & 0.1 & 0.1 & 0.1 & 0.1 & 0.1 & 0.1 & 0.1 \\
\hline$P_{7}^{\mathrm{f}}$ & $P_{7,1}$ & 0.033 & 0.033 & 0.033 & 0.033 & 0.033 & 0.033 & 0.033 & 0.033 \\
\hline$P_{8}^{\mathrm{g}}$ & $P_{8,1}$ & 0.55 & 0.99 & 2.4 & 25 & 0.55 & 1.1 & 2.9 & 270 \\
\hline$P_{9}^{\mathrm{g}}$ & $P_{9,1}$ & 0.22 & 0.33 & 0.54 & 0.93 & 0.22 & 0.35 & 0.59 & 0.99 \\
\hline
\end{tabular}

${ }^{\mathrm{a}} \mathrm{Cu}$ consumption in the manufacturing industries

$\mathrm{b}$ Transfer of new scrap

${ }^{c}$ Ratio of short-term to long-term products

${ }^{\mathrm{d}}$ Consumption of long-term/short-term products [ $\tau$ mean residence time (year), $\sigma$ standard deviation from $\tau$ (year)]

${ }^{\mathrm{e}}$ Transfer gangue

${ }^{\mathrm{f}}$ Transfer slag

${ }^{\mathrm{g}}$ Ratio old scrap to residues for long-term/short-term products
$P_{2}(t)=\frac{\text { new scrap }(\mathrm{t})}{\text { production of goods }(\mathrm{t})}$ for the period between 1900 and 1990 can be derived from the data in Fig. 3. The development is practically constant as a function of time. The corresponding parameter value for $P_{2}$ is shown in Table 3 . The ratio of copper consumption in short-term to long term products (parameter $P_{3}$ ) is estimated using the data in Table 2. (For the products not clarified in Table 3 it was assumed that the ratio of long-term to short-term products is $4: 1$, similar to the classified ones.) The parameters $P_{6}, P_{7}$ relating to losses during $\mathrm{Cu}$ extraction (processes 2,3 ) are calculated by means of the values listed in the section on system analysis. The values for $P_{3}, P_{6}$ and $P_{7}$ are also included in Table 3.

$$
\begin{aligned}
& P_{4}=\mathrm{k}_{\text {longterm }}\left(t, t^{\prime}\right), P_{5}=\mathrm{k}_{\text {shortterm }}\left(t, t^{\prime}\right), P_{8}, P_{9} \text { (transfer } \\
& \text { functions and separation of the output from the two } \\
& \text { consumption processes) }
\end{aligned}
$$

The two-parametric Gauss functions (Bader and Baccini 1993; Baccini and Bader 1996), corresponding to normally distributed residence times, are well-established and simple dynamic transfer functions.

The parameters, thus, express:

$\tau_{I}, \tau_{M}$ : Mean residence time of the copper in the consumption processes of long-term and short-term products

$\sigma_{I}, \sigma_{M}$ : Standard deviations of the residence times $N_{0}^{(I)}, N_{0}^{(M)}$ : Normalization factors

Figure 4 illustrates $k\left(t, t^{\prime}\right)$ as a function of time.

$$
P_{4}=k_{\text {longterm }}\left(t, t^{\prime}\right)=\frac{1}{N_{0}^{(I)}} e^{\frac{-\left(t-t^{\prime}-\tau_{\mathrm{I}}\right)^{2}}{2 \sigma_{\mathrm{I}}^{2}}}
$$

$P_{4}, P_{5}, P_{8}$ and $P_{9}$ calibrated indirectly). The shown values are given with two decimal places 


$$
P_{5}=k_{\text {shortterm }}\left(t, t^{\prime}\right)=\frac{1}{N_{0}^{(M)}} e^{\frac{-\left(t-t^{\prime}-\tau_{\mathrm{M}}\right)^{2}}{2 \sigma_{\mathrm{M}}^{2}}}
$$

$P_{8}(t), P_{9}(t)$ : Similarly as above, these functions are assumed for a first approximation to be constant as a function of time.

In contrast to the parameter functions above, $P_{4}, P_{5}, P_{8}$ and $P_{9}$ cannot be calibrated directly from the available raw data. They are calibrated by mathematical simulations. For $\tau_{I}, \sigma_{I}$ and $\tau_{M}, \sigma_{M}$, different values within a reasonable range are assumed as follows (Table 3 ):

- Four equidistantly distributed values between the two extreme mean residence times of 30 and 90 years were selected for $\tau_{I}$.

- Reasonable values for $\tau_{I}, \tau_{M}$ and $\sigma_{M}$ were assumed for each value of $\tau_{I}$.

The values for $P_{8}$ and $P_{9}$ are calibrated in such a way that the mathematical simulation (1) describes the development for the total old scrap according to Fig. 3, and that (2) the ratio of the transfer coefficients $k_{83}$ and $k_{93}$ is equal to 2 . The ratio 2 is based on the assumption that the separation efficiency for old long-term products is twice as high as that for old short-term products. To allow a comparison between the linear Eq. (7a) and logistic Eq. (7b) growth, the same sets of parameter for $\tau_{I}, \sigma_{I}, \tau_{M}$ and $\sigma_{M}$ were chosen for both. This results in four scenarios for linear and logistic copper consumption (Table 3).

The differences in character of the parameter functions are clearly visible in Table 3 . All parameter functions $\left(P_{1}, P_{2}\right.$, $\left.P_{3}, P_{6}, P_{7}\right)$ calibrated from raw data are the same for all scenarios. The "varied" parameter functions $\left(P_{4}, P_{5}\right.$, $\left.P_{8}, P_{9}\right)$, however, are the actual "scenario parameters" (Table 3).

\section{Mathematical simulation}

All sets of parameters in Table 3 and a series of other calculations were performed with the program SIMBOX on a Pentium PC. SIMBOX solves iteratively the system of Eqs. (1), (2), (3), (4), (5), and (6). The time range was always chosen between 1900 and 2100 . The time steps used

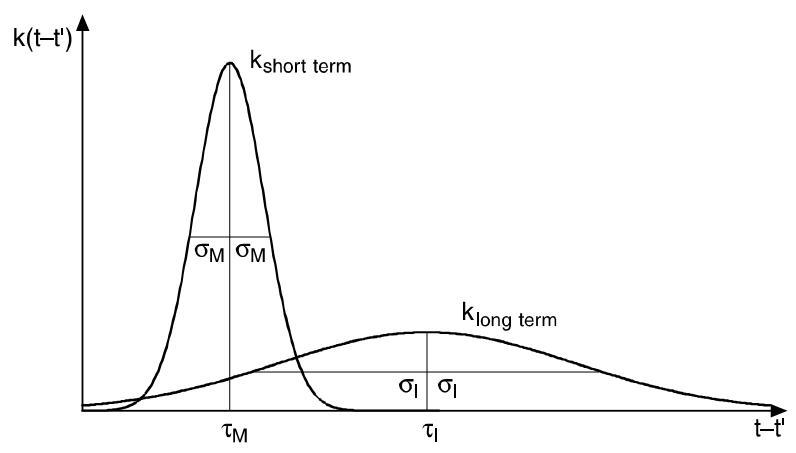

Fig. 4

Transfer function of the consumption behaviour, $k_{\text {longterm }}$ and $k_{\text {shortterm }}$ using the parameters from scenario 1 in the calculation are adapted automatically so that the prescribed threshold of convergence is not exceeded.

\section{Results}

The results of the simulation for the important quantities are listed in Table 4 in the case of linear growth. The values of the varied parameters are also shown in the same table for clarification purposes. Figure 5 illustrates realtime inventories of the copper fluxes for the years 1900, 1990 and 2100 from scenario 2.

Figure 6 illustrates the development of important fluxes and stocks of two scenarios as a function of time (Fig. 6a, scenario 2 linear, b, scenario 6 logistic).

The considerable influence of residence times on the stocks in long-term and short-term products, as well as in landfill, is clearly visible in Table 4: the longer the residence times, the greater the intermediate stocks (shortterm and long-term products). This is due to the longer "stock development phase" with greater residence times, but equal consumption in all four scenarios. Development of stock is correspondingly slower in landfill.

A comparison of stocks and fluxes for the years 1900, 1990 and 2100 in Fig. 5 reveals the significant increase in consumption (factor 60 between 1900 and 2100!) and the massive transfer of stock from the ore deposits into longterm products and landfills.

Figure 6 finally illustrates the difference between linear and logistic consumption over the same time period (1900-1990). With logistic consumption, all the fluxes as well as the long-term and short-term product stocks reach their (asymptotic) equilibrium around the year 2050. The resulting short-term and long-term product stocks in the year 2100 are half the size of those obtained with linear consumption. This difference between linear and logistic consumption will of course increase in the more distant future.

For a more detailed discussion, see next section.

\section{Discussion and interpretation of the results}

\section{Recycling rate and separation efficiency}

The original variables are not always the only variables of relevance for measurements and analyses. Quite often, functions of the variables are more important. To assess the recycling rate, many studies calculate characteristics without defining the system on which they are based. The following characteristics are used to discuss the simulated copper household:

Recycling rate $R$ :

$$
R(t)=\frac{A_{83}(t)+A_{93}(t)}{A_{56}(t)+A_{57}(t)} \quad\left(\frac{\mathrm{Cu} \text { in old scrap }}{\mathrm{Cu} \text { in consumed products }}\right)
$$


Table 4

Varied parameters and important quantities for the four scenarios with linear growth

\begin{tabular}{|c|c|c|c|c|c|c|c|c|c|}
\hline Scenario & $\begin{array}{l}\tau_{I}^{\mathrm{a}} \\
\text { (years) }\end{array}$ & $\begin{array}{l}\sigma_{I}^{\mathrm{b}} \\
\text { (years) }\end{array}$ & $\begin{array}{l}\tau_{M}^{\mathrm{a}} \\
\text { (years) }\end{array}$ & $\begin{array}{l}\sigma_{M}^{\mathrm{b}} \\
\text { (years) }\end{array}$ & $\begin{array}{l}k_{83}^{\mathrm{c}} \\
(\%)\end{array}$ & $\begin{array}{l}k_{93}^{\mathrm{d}} \\
(\%)\end{array}$ & $\begin{array}{l}\text { Stock short-term } \\
\text { products } M^{(7)} 1990 \\
\text { (kg per capita) }\end{array}$ & $\begin{array}{l}\text { Stock long-term } \\
\text { products } M^{(6)} 1990 \\
\text { (kg per capita) }\end{array}$ & $\begin{array}{l}\text { Stock landfill } \\
M^{(10)} \\
1990 \quad(\mathrm{~kg} \text { per } \\
\text { capita) }\end{array}$ \\
\hline 1 & 30 & 20 & 5 & 3 & 36 & 18 & 9.2 & 200 & 230 \\
\hline 2 & 50 & 30 & 10 & 7 & 50 & 25 & 18 & 280 & 160 \\
\hline 3 & 70 & 40 & 15 & 10 & 70 & 35 & 26 & 310 & 120 \\
\hline 4 & 90 & 50 & 20 & 15 & 96 & 48 & 34 & 330 & 88 \\
\hline
\end{tabular}

${ }^{a}$ Mean residence time of copper in long-term and short-term product consumption processes

${ }^{\mathrm{b}}$ Standard deviations of residence times

${ }^{\mathrm{c}} k_{83}=\frac{A_{83}}{A_{68}}$ : Transfer coefficient of old scrap in long-term products

${ }^{\mathrm{d}} k_{93}=\frac{A_{93}}{A_{68}}$ : Transfer coefficient of old scrap in short-term products

Separation efficiency $E$ :

$$
E(t)=\frac{A_{83}(t)+A_{93}(t)}{A_{68}(t)+A_{79}(t)}
$$$$
\left(\frac{\mathrm{Cu} \text { in old scrap }}{\mathrm{Cu} \text { in disposed products }}\right)
$$

The values for $R$ and $E$ for the years 1990 and 2100 and a few scenarios are listed in Table 5.

The recycling rate for 1990 corresponds approximately for all scenarios to the predefined fraction of old scrap (Fig. 3). Separation efficiency always ranges between the transfer coefficients $k_{83}$ and $k_{93}$ (see Table 4), which can easily be proven mathematically. In 2100 , the transfer coefficients are closer to $k_{83}$, as the fraction of old scrap in long-term products is higher than in 1990 . The recycling rate $R$ also increases between 1990 and 2100. In the logistic scenario, $R$ is almost as high as $E$ in 2100 .

By means of parameters $R$ and $E$, calibration of the model (see next section) can be compared with values from the literature. In the section on the "Monitoring program" how the recycling rate in a dynamic system can lead to misinterpretations is discussed.

\section{Discussion of the calibration}

As already discussed in "Calibration of the model", the parameter functions $P_{4}, P_{5}, P_{8}$, and $P_{9}$ (including the parameters $\tau_{I}, \sigma_{I}, \tau_{M}, \sigma_{M}, k_{83}$ and $k_{93}$ ) have the largest uncertainty with regard to calibration. Therefore, the parameters $\tau_{I}, \sigma_{I}, \tau_{M}$ and $\sigma_{M}$ are varied within the potentially greatest range. The values for $k_{83}$ and $k_{93}$ are then obtained through calibration as described in "Model specification".

As illustrated in Table 4, the transfer coefficients $k_{83}$ and $k_{93}$ as well as the separation efficiency (Table 5) vary also within a very large range. The same also applies to the copper stocked in short-term and long-term products as well as in landfills. The first two stocks grow with increasing residence time as opposed to the stock in landfills. This correlation only prevails as long as the copper consumption $(\mathrm{Cu}$ in the semi-manufactured products) is clearly predefined. Calibration is discussed in the following, with literature data not included in the model:
- Residence times $\left(\tau_{I}, \tau_{M}\right)$ : According to past investigations, the estimated residence times in long-term $\left(\tau_{I}\right)$ and short-term $\left(\tau_{M}\right)$ products amount to about 50 and 10 years respectively (Baccini and Brunner 1991). Similar values have been published on the recycling of copper materials (Deutsches Kupferinstitut 1990; Arpaci and Vendura 1992). Considering residence times, scenario 2 (and scenario 6 logistic) thus provide the most realistic values.

- Stocks $M^{(6)}, M^{(7)}$ : The available data on Cu stocks in the anthroposphere are scarce. Consumption of copper containing short-term products has been studied for private Swiss households (Baccini et al. 1993). Here, the measured copper stock in short-term products amounts to $7 \mathrm{~kg}$ per capita, and is situated within the range obtained with scenario 1 . Since short-term products are not only found in private households, but also in industry, trade and agriculture, the total shortterm stock in Switzerland is more likely to amount to $10-20 \mathrm{~kg}$ per capita (scenario 2). According to a Swedish material household study (Bergbäck and Johansson 1996), the technosphere of Stockholm for 1995 revealed a total stock (short- and long-term products) of approximately $140 \mathrm{~kg}$ per capita. This value is 1.5 to 2.5 times smaller than the consumption stocks $\left(M^{(6)}\right.$ and $M^{(7)}$; Table 4$)$ determined by calibration. This value is, however, of the same order of magnitude. The difference is mainly attributed to the different population densities between urban Stockholm (>1000 per capita per $\left.\mathrm{km}^{2}\right)$ and rural USA $\left(<200\right.$ per capita per $\left.\mathrm{km}^{2}\right)$. The higher the population density, the lower the material stock per capita for pipe networks. A further reason is the difference in building structures between Stockholm and the USA. This can be exemplified by the use of $\mathrm{Cu}$ in air-conditioning systems which is significant in the USA (Table 2), but insignificant in Sweden. The stock value of $140 \mathrm{~kg}$ per capita speaks nonetheless for lower residence times (scenario 1 or possibly 2 ).

- Separation efficiency $E$ : Cu separation efficiency data covering the entire field of waste management (processes 8, 9) could not be identified. However, values for $E$ are known for individual waste management 

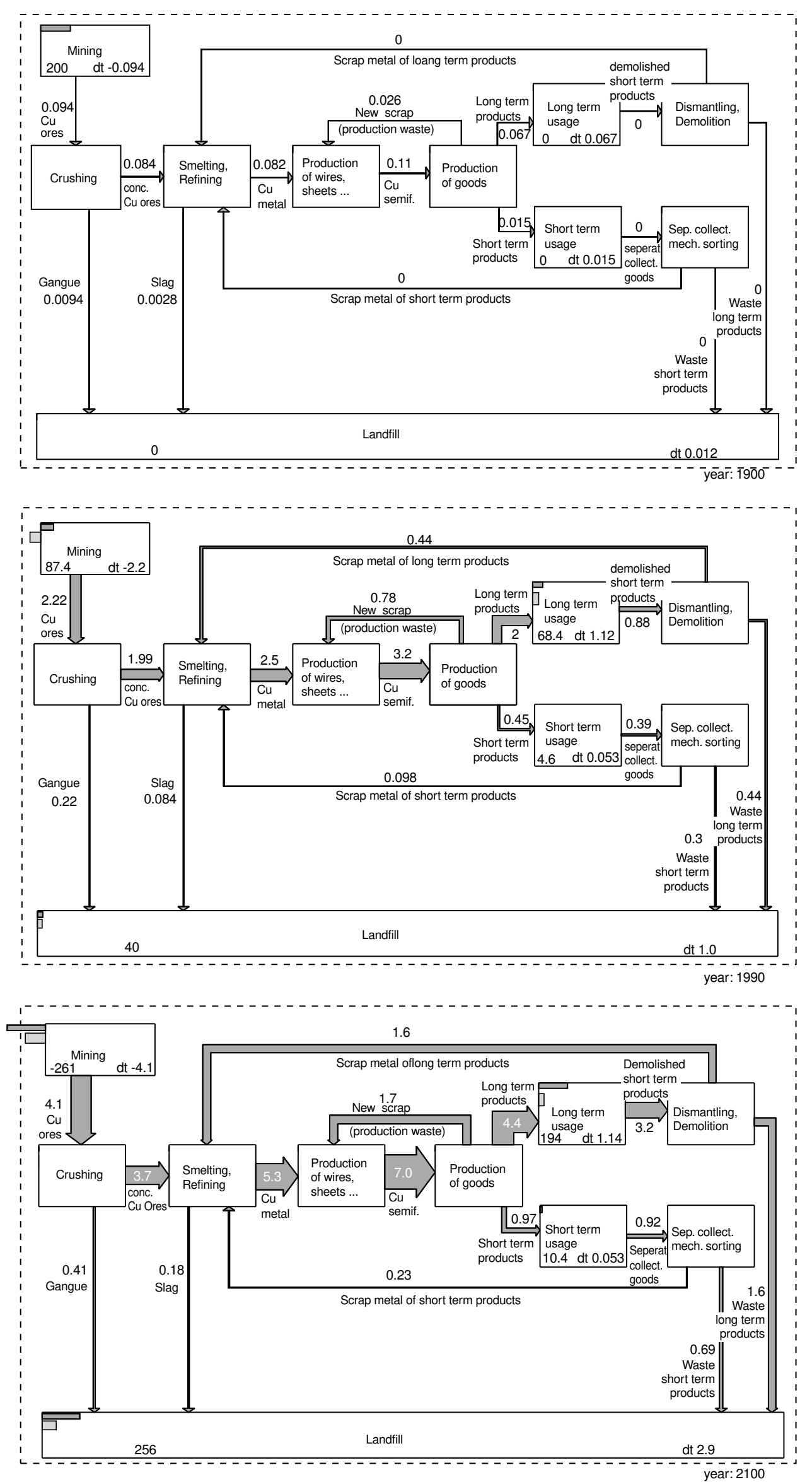

Fig. 5

Real-time inventories of the copper fluxes in the USA for the years a 1900, b 1990 and c 2100, including the parameters from scenario 2, expressed in (million tons per year; fluxes) and (million tons; stocks). The numbers in the lower left corner of the boxes express the stocks, and the numbers in the right corner denote the changes in stock rates. The width of the arrows is proportional to its value, and the length of the lower columns in the upper left corner of the boxes is proportional to the changes in stock rate. The length of the upper columns in the upper left corner is proportional to the stock. An outer column expresses a decrease in stock, an inner column shows an increase in stock 


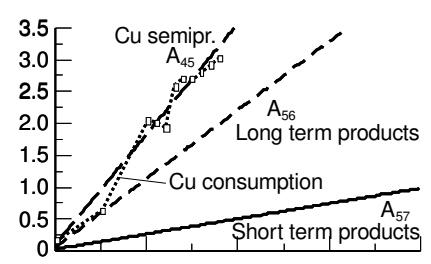

${ }^{3.5}$ - Scrap long term products $A_{83}$
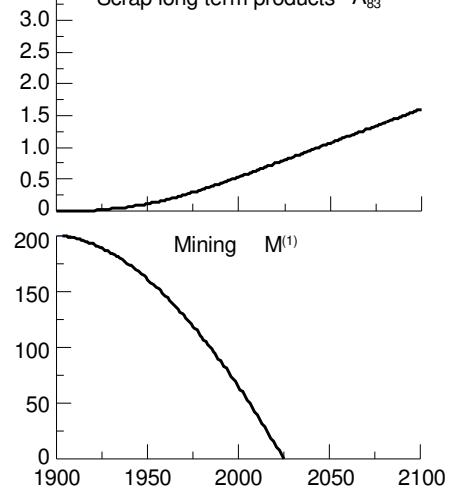

a
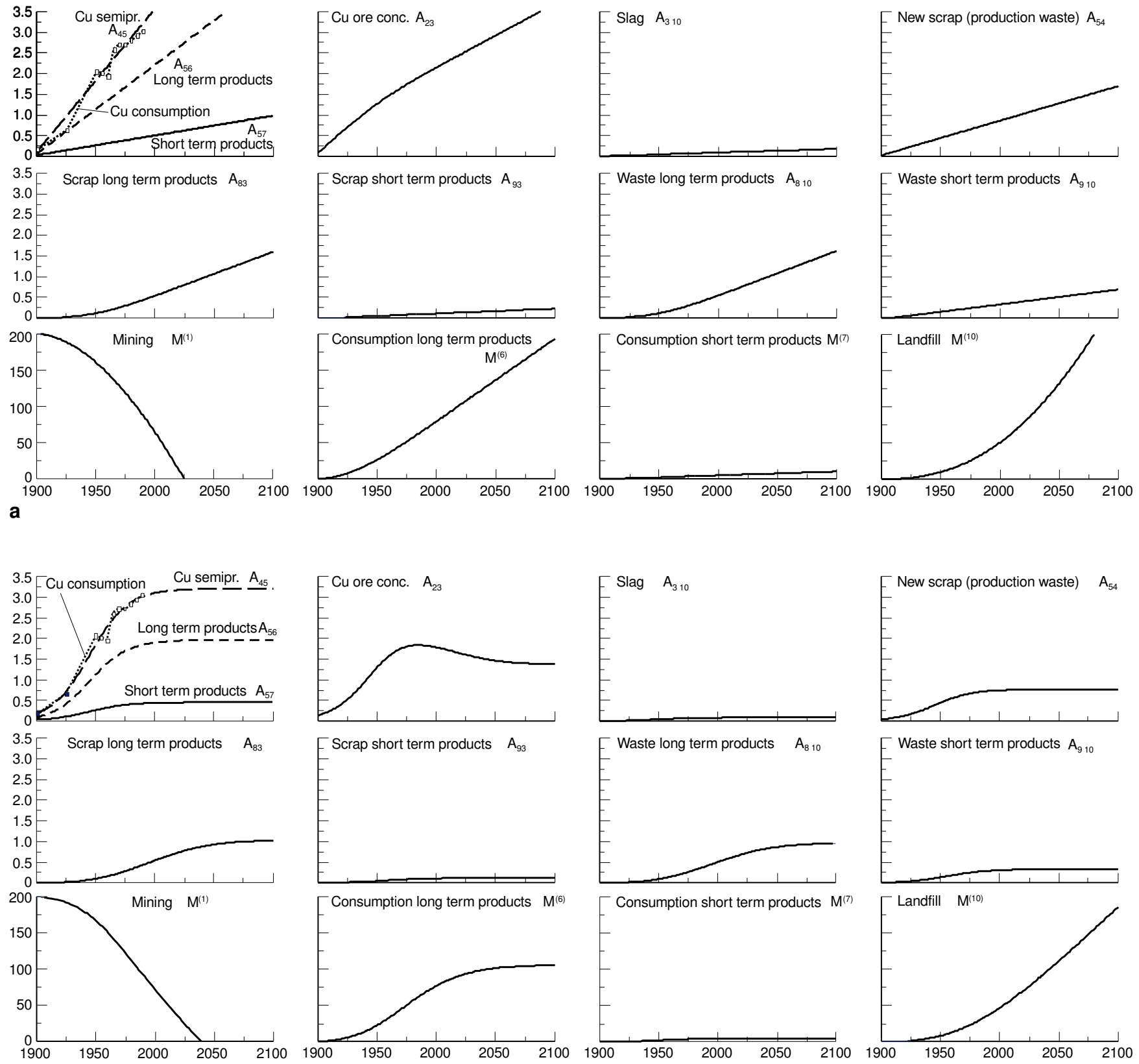

b

Fig. 6

Development of important fluxes and stocks for scenario 2 (a) and scenario 6 (b) as a function of time. The values for the fluxes are expressed in million tons per year and for the stocks in million tons

processes. In a car scrapping plant, $40 \%$ of the copper contained in cars reaches the scrap market (Frei et al. 1993), $35 \%$ is transferred to the combustible light metal fraction (residues from shredder plants) and $25 \%$ remains in ferrous scrap. If waste management for all short-term products is the same as for the cars, then the value $k_{93}$ is equal to $40 \%$. This value is situated between scenarios 3 and 4 (Table 4). In two studies (Deutsches Kupfer-Institut 1990; Arpaci and Vendura

1992), Sibley et al. (1995) estimate the overall separation efficiency (losses during scrap smelting are neglected) using trend analyses for products in waste management processes. The two studies obtain totally different values:

In Deutsches Kupfer-Institut (1990) and Arpaci and Vendura (1992), a recycling rate [see Eq. (9a)] of $40 \%$ is assumed for Germany. Without establishing a waste treatment balance, the copper separation efficiency is assumed to be $>80 \%$. In a next step, a so-called real recycling rate is introduced. To calculate a real recycling rate, a mean residence time of 33 years is assumed. The current old scrap flux, which is divided by the $\mathrm{Cu}$ consumption of 33 years ago, results in the very high rate of $80 \%$. 
Table 5

Recycling rate $(R)$ and separation efficiency $(E)$ calculated for the scenarios 1-4 and 6 (lin linear; log logistic) for 1990 and 2100

\begin{tabular}{|c|c|c|c|c|}
\hline \multirow[t]{2}{*}{ Scenario } & \multirow{2}{*}{$\frac{R(\%)}{1990}$} & \multirow[b]{2}{*}{2100} & \multirow{2}{*}{$\frac{E(\%)}{1990}$} & \\
\hline & & & & 2100 \\
\hline 1 (lin) & 22 & 27 & 31 & 32 \\
\hline 2 (lin) & 22 & 34 & 42 & 44 \\
\hline 3 (lin) & 22 & 42 & 57 & 62 \\
\hline 4 (lin) & 22 & 50 & 74 & 83 \\
\hline 6 (log) & 23 & 47 & 43 & 47 \\
\hline
\end{tabular}

According to a study from the USA, $E$ was estimated at $30 \%$ (Table 6; Sibley et al. 1995). This corresponds to scenario 2 (Table 5) of the model presented in this study. In this American study, the recycling rate $(R=22 \%)$ is the same as the one assumed by our model (Table 5 ). The study also compares copper with 22 other metals, some of which are listed in Table 6. Compared with the other important metals for $\mathrm{Al}$ and $\mathrm{Zn}, R$ and $E$ are as low as for $\mathrm{Cu}$. Separation efficiency of $\mathrm{Pb}$ and especially $\mathrm{Au}$ and $\mathrm{Fe}$, is significantly higher than of $\mathrm{Cu}$.

For further discussion and comparison with the logistic growth, the values from scenario 2 are used. Since the model cannot be exactly calibrated with the available data material, more accurate estimations of residence times $\tau_{I}$ and $\tau_{M}$, and particularly of the transfer coefficients $k_{83}$ and $k_{93}$ are required.

\section{Discussion of the actual copper fluxes and stocks (1990; Fig. 5b)}

Till 1990, about 110 million tons of copper were mined for USA consumption, of which approximately 70 million tons are stocked in long-term and short-term products, and 40 million tons are currently landfilled and no longer usable. Three quarters of the copper fluxes in landfills are due to lack of efficient separation in the waste management processes (waste treatment, dismantling/demolition). The copper stocks in the long-term products are approximately 15 times higher than those in short-term products. Therefore, the copper contained in the longterm products could become the most important copper resource in the future.

\section{Comparison of linear and logistic growth}

Figure 6 illustrates the development of important fluxes and stocks for linear (scenario 2, Fig. 6a) and logistic growth (scenario 6, Fig. 6b) as a function of time. Both scenarios correctly describe the development to this day (1900-1990) in the sense that they approximate relatively well past $\mathrm{Cu}$ consumption (Fig. 3), i.e. the sum of long-term and short-term products (Fig. 2) as well as the old scrap within the elements of uncertainty (first graph in Fig. $6 a, b)$. Development of both scenarios will vary significantly in the future, as logistic growth reaches saturation between 2000-2050, in contrast to linear growth. Depletion time of the copper stock in mining is only insignificantly delayed by the assumption of a saturation

\section{Table 6}

Recycling rate $(R)$ and separation efficiency $(E)$ for various metals [compare Eqs. $(8 \mathrm{a}, \mathrm{b})$ ], calculated for the USA on the basis of Sibley et al. (1995). In this study, separation efficiency is calculated by means of typical residence times of the most important products

\begin{tabular}{llll}
\hline Metal & $R(\%)$ & & $E(\%)$ \\
\cline { 1 - 2 } Copper & 22 & 30 \\
Iron & 27 & 95 \\
Aluminium & 25 & 36 \\
Zinc & 12 & 21 \\
Lead & 57 & 64 \\
Gold & 18 & 90 \\
\hline
\end{tabular}

in growth (mining graphs in Fig. 6a,b). This is due to the initial amount of the assumed mineable ore in the USA in 1990 of about 180 million tons. More optimistic values for depletion times of the copper reserves would amount to about 200-300 years instead of 50 years. However, the main problem remains the same and is characteristic for non-renewable resources: Only a significant increase in residence times, recycling rates or use of copper already landfilled and replacement would allow the long-term use of copper.

The possibilities "increase in recycling" and "replacement by other materials" can roughly be discussed on the basis of Table 2. For instance, replacement of copper by glass fibre cables in telecommunication equipment can lead to an approximately $12 \%$ decrease in copper consumption in long-term products.

\section{Sensitivity analyses and propagation of error}

Sensitivity analyses and propagation of error demonstrate the influence of parameter changes on the variables (Baccini and Bader 1996; Bader and Baccini 1996). The objective is to assess, on the one hand, which parameters have what influence on what quantities and, on the other, the effects of parameter uncertainties. This information is important for controlling the system and for investigating a moitoring program. Figure 7 compares a $20 \%$ uncertainty of both parameters $\tau_{I}$ and $k_{83}$ on the residues in long-term products, thus revealing that an uncertainty in $k_{83}$ has approximately 1.5 times greater influence on this copper flux.

\section{Monitoring program}

The considerations in "Recycling rate and separation efficiency" revealed that the greatest uncertainties are associated with residence times and transfer coefficients of the waste management processes. Finally, in "Discussion of the actual copper fluxes and stocks", it is shown that these parameters represent the most important quantities in the copper household. A more profound knowledge of these transfer coefficients is therefore of extreme importance for a monitoring program. These coefficients are also necessary to calculate the separation efficiency $E$ and recycling rate $R$. They characterize separation and recycling for a stationary and dynamic system, respectively, close to 
the state of equilibrium. For a dynamic system outside the state of equilibrium, the dynamic recycling rate could be used instead of $R$. It can be defined as follows:

$R_{\text {Dyn }}^{\text {long term }}\left(t_{I p}\right)$ expresses the overall percentage of the longterm product input $A_{56}\left(t_{I p}\right)$ at time $t_{I p}$, leaving at some time $t_{O p} \geq t_{I p}$ the long-term usage process as old scrap in long-term products. For our specific model, for example, the following applies:

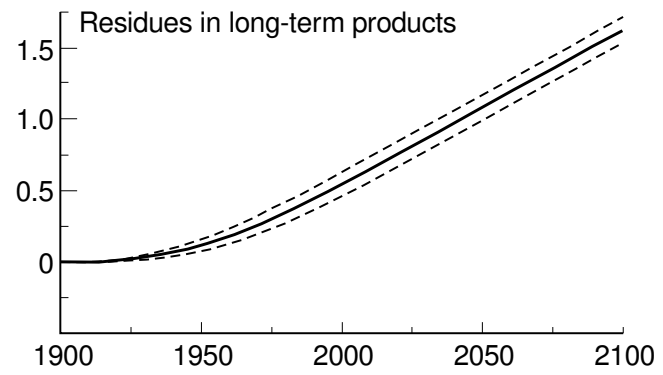

a

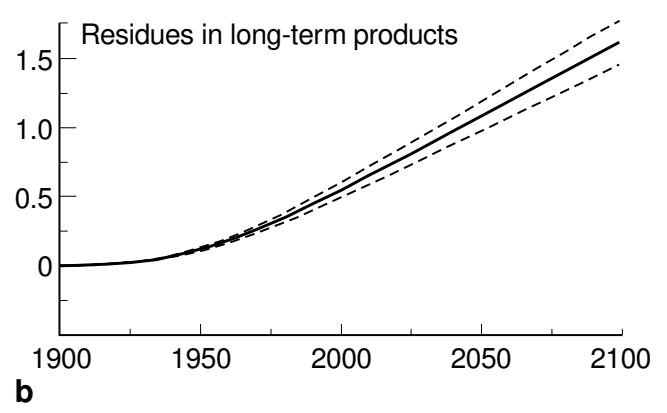

Fig. 7

Propagation of a $20 \%$ uncertainty of the parameters $\tau_{I}$ (a) and $k_{83}$ (b) on the residues in long-term products $\left(A_{810}\right)$

$$
R_{\mathrm{Dyn}}^{\text {long term }}\left(t_{I p}\right)=\int_{t_{I p}}^{\infty} k_{83}\left(t_{O P}\right) \cdot k_{\text {long term }}\left(t_{O P}, t_{I p}\right) \cdot d t_{O P}
$$

The same applies to the short-term products.

Information on the transfer coefficients of separation is important also for these dynamic recycling rates. Figure 8 clearly shows the significant differences between $R$ and $R_{\text {Dyn }}^{\text {longterm }}$ for the studied system. Figure 8 illustrates the fact that the mostly used recycling rate $R$ tends only towards $R_{D y n}$ close to the point of equilibrium $(t \rightarrow \infty)$ as mentioned above.

Use of the dynamic recycling rate presupposes exact knowledge of the dynamics of a system. This is certainly not yet the case for the copper household. Therefore, the "real recycling rate" defined in (Deutsches Kupfer-Institut 1990; Arpaci and Vendura 1992) is a rather daring assumption.

\section{Conclusions}

1. By means of a relatively limited and inaccurate set of data it is possible to establish a first approximation of the regional management of copper metal. The model was not developed to reach maximum accuracy concerning the quantification of the actual copper fluxes and stocks. Residence times of the copper-containing products and transfer coefficients of copper in recyclable products are responsible for the most important data gaps in the system. This gap can be filled by a calibration of the model. Residence time in consumption products is varied (scenarios) to allow
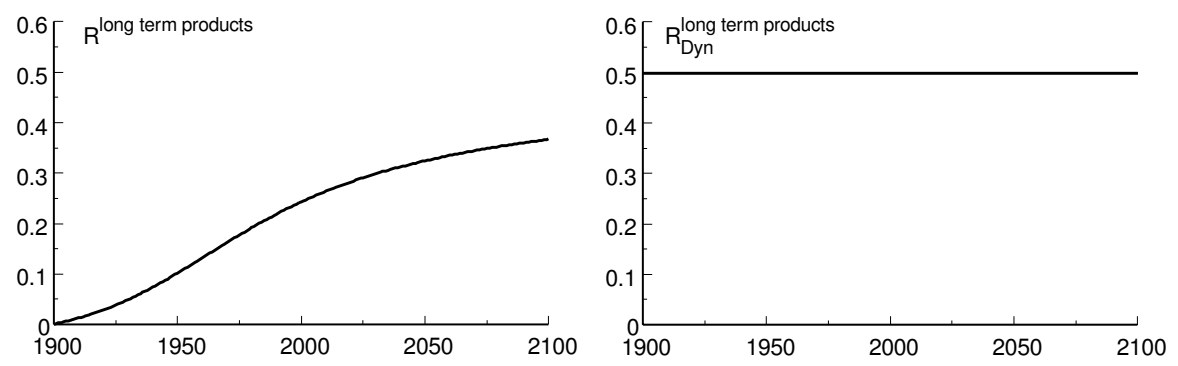

a linear growth
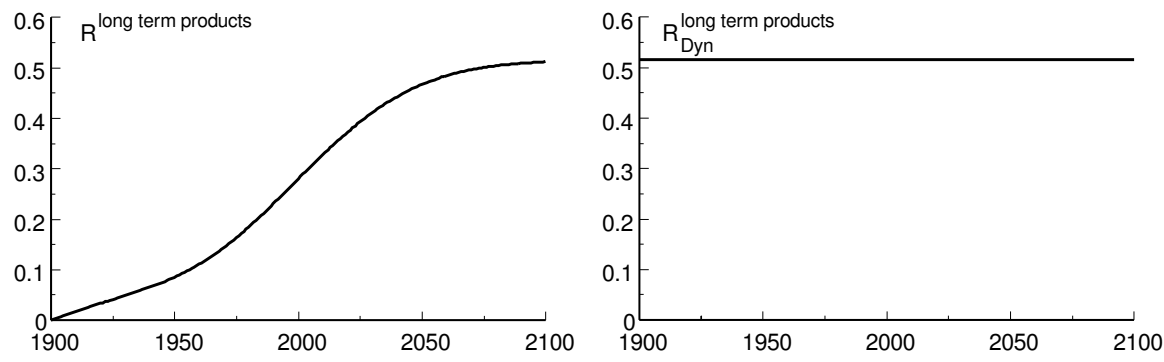

Fig. 8

Recycling rates $R^{\text {longterm }}$ (stationary) and $\mathrm{R}_{\text {Dyn }}^{\text {longterm (dynamic) in the long-term }}$ products for scenario 2 (a) and scenario 6

b logistic growth (b) 
calculation of the ranges in transfer coefficients. In this way the parameters best fitting the empirical data can be found.

2. This method shows that the copper management of the 20th century (illustrated by an example from the USA) has contributed to the formation of two new "ore deposits" of the same order of magnitude as the currently still available deposits (about 90 million tons), i.e. the copper stock in consumption products (approximately 70 million tons) and the no longer used copper stock in landfills (approximately 40 million tons). Concerning the consumption stock, the copper deposit in long-term products is greater than that in short-term products. If the gangue material (residues from copper ore crushing) is neglected, the waste management processes are to $90 \%$ responsible for the loss in copper recycling.

3. Both linear and logistic scenarios (with saturation in consumption) reveal that the current economically mineable $\mathrm{Cu}$ stocks will be mined in 30 to 50 years if the existing management system is not changed. In case of a re-orientation, the use of copper in the consumption stock as a "new resource" appears to be the most promising strategy. Waste management processes will in future have to increase their copper recycling rates. Based on current economic considerations, recycling of copper from existing landfills is not a sound solution, as it is diffusely distributed, e.g. in products manufactured from steel scrap (up to $4 \mathrm{~g} / \mathrm{kg}$; Bundesamt der deutschen Schrottwirtschaft 1984; Höffken et al. 1988), in municipal solid waste (MSW) bottom ash landfills (5-8 g/kg; Zeltner 1998; Frey and Hugentobler 1996), in municipal waste landfills $(1-2 \mathrm{~g} / \mathrm{kg}$, approximately five times less than in MSW bottom ash) or in construction waste landfills $(<1 \mathrm{~g} / \mathrm{kg})$. For reasons of sustainable, long-term copper usage (and metals in general), this type of landfilling should be discontinued as it is neither a quantitatively nor a qualitatively reasonable solution.

4. The very low copper price (see "Introduction") does not include the limitation of copper ore deposits. Even the increasing demand does not lead to rising prices. Increasing demand is mainly covered by the expansion of established copper mines or the opening of new mines. Both are very cheap. An analysis of total development costs of 60 new mine projects indicates that an average of $\$-8100 /$ ton of copper capacity must be invested to develop a new mine (Jolly and Edelstein 1989). To enlarge an established mine approximately $\$-3200 /$ ton of copper capacity has to be invested (Jolly and Edelstein 1989). In the same order of magnitude are the costs to enlarge the smelting and refining capacities. The costs to develop new mechanical sorting and smelting processes to increase the efficiency of copper recycling are much higher than all these costs together. The copper stocks in mobile and immobile goods have had a value of about $\$-600$ per capita in the year 1990. From this stock approximately $5 \mathrm{~kg}$ per capita and year with a value of \$-10 are transferred from the consumption process to waste treatment processes. The low prices for mining, smelting and refining copper are the reason for the very slow improvement in the amount of recycled copper. The situation of copper as a resource is very similar to the fossil energies. Economic instruments are necessary to minimize copper consumption in order to use copper stocks in our goods more efficiently, similarly to the use of alternative energies.

5. Re-orientation of the copper management system, therefore, requires changes in the field of "consumption stock management". Successful control of such changes is only ensured by defining system-specific parameters, such as stock inventories, recycling rates and recycling efficiency. This will require a more accurate calibration of the model by means of the presented method, and development of future, systemspecific data acquisition.

\section{References}

Arpaci E, Vendura T (1992) Recycling von Kupferwerkstoffen. VDI Berichte Nr 917, Verein Deutscher Ingenieure, Düsseldorf BACCINI P, BADER H-P (1996) Regionaler Stoffhaushalt. Spektrum Akademischer Verlag, Heidelberg

BACCINI P, BRUnNer PH (1991) Metabolism of the anthroposphere. Springer, Berlin Heidelberg New York

Baccini P, DaXbeck H, Glenck E, Henseler G (1993) Metapolis Güterumsatz und Stoffwechselprozesse in den Privathaushalten einer Stadt. NFP Stadt und Verkehr, vol 34, Zürich

BADER H-P, BACCINI P (1993) Monitoring and control of regional material fluxes. In: Schulin $\mathrm{R}$, Desaules A, Webster R, von Steiger B (eds) Soil monitoring. Birkhäuser, Basel, pp 2534

BADER H-P, BACCINI P (1996) Systemmodell und Simulationprogramme im Umweltmanagement - Eine kritische Analyse zum Stand der Technik. GAIA 5, no 6, Spektrum Akademischer Verlag, Heidelberg

BERgBäck B, JahANsson K (1996) Metalle i stad och land - kretslopp och kritisk belastning Lägesrapport. Natur Vards Verket 4677

BisWAS AK, DAVENPORT WG (1994) Extractive metallurgy of copper. Pergamon, Oxford

BLACK WT, LyMAN WS (1990) The flow of copper to US markets. The Institute of Metals: Copper 90 Refining Fabrications Markets, Västeras, Sweden

Bruch KH, Gohlke D, Kögler C, Krüger J, Reuter M, Röpenack I, Rомвасн E, Rомвасн G, WinkLeR P (1996) Sachbilanz einer Ökobilanz der Kupfererzeugung und -verarbeitung. Metall 4/ 5/6, Heidelberg

Bundesamt DeR Deutschen Schrottwirtschaft e.V. (1984) Recycling - Vom Schrott zum Stahl. Verlagsgruppe Handelsblatt, Düsseldorf

Department of Economic and Social Development Statistical Office (1992) 1990 International trade statistics yearbook. United Nations, New York

Deutsches Kupfer-Institut (DKI) Recycling von Kupferwerkstoffen. DKI-Informationsdruck, Berlin

Frey R, Hugentobler E (1996) Beschrieb Versuchsanlage/Resultate/Auswertungen. In: Versuchsbericht HSR-Pilotversuche Klus. Arbeitsgemeinschaft Holderbank-Schmelz-Redox (HSR), Zürich Frei M, KüNG A, Schuler B (1993) Kupfer-Flüsse in der Automobilbranche. Vertiefungsblock-Arbeit ETHZ, Zürich 
Höfrken E, Hammer R, Schicks H, Ullrich W (1988) Chemische Zusammensetzung und Verwendung von aufbereitetem Schrott. Stahl und Eisen 17, Düsseldorf

Jolly JLW, EdeLSTEIN DL (1989) Copper. In: Minerals yearbook. US Department of Commerce, Bureau of Mines, Washington, pp 333-386

Metallgesellschaft AG (1992) Metallstatistik 1982-1992, vol 80 (also vols 70, 60, 50, 30, 10). Metallgesellschaft AG, Frankfurt am Main
Sibley SF, Butterman WC et al. (1995) Metals recycling in the United States. Resour Conserv Recycling 15:256-267

Verband der Automobilindustrie VDA (1997) International Auto Statistics. VDA, Frankfurt

VoN ARx U (1996) Kupfer in der Schweiz. Bundesamt für Umwelt, Wald und Landschaft (BUWAL), Bern

Zeltner C (1998) Petrologische Evaluation der thermischen Behandlung von Siedlungsabfällen über Schmelzprozesse. Dissertation, EAWAG Dübendorf, ETH Zürich 